\title{
Wear resistance of geosynthetic interfaces constituted by geomembranes and geospacers
}

\author{
Resistência ao desgaste de interfaces geossintéticas \\ constituídas por geomembranas e geoespaçadores
}

\section{Heraldo Nunes Pitanga \\ Professor adjunto, DTECH, \\ Universidade Federal de São João del Rei, \\ Campus Alto Paropeba, \\ Ouro Branco-MG, Brasil. \\ heraldopitanga@ufsj.edu.br}

\section{Orencio Monje Vilar}

Professor Titular,

Escola de Engenharia de São Carlos (EESC), Universidade de São Paulo,

São Carlos-SP, Brasil.

orencio@sc.usp.br

\section{Jean-Pierre Gourc}

Professor titular, LTHE,

Université Joseph Fourier (Grenoble I),

Grenoble, França.

jpgourc@ujf-grenoble.fr

\section{Resumo}

Esse artigo apresenta os resultados de um estudo experimental que visa a avaliar o efeito do desgaste superficial sobre as propriedades de atrito de interfaces geossintéticas constituídas por geomembranas. Os ensaios foram realizados em equipamento de plano inclinado e os resultados demonstram as diferentes sensibilidades das interfaces, testadas ao processo de desgaste. Para os tipos particulares de interfaces consideradas no programa experimental, constatou-se que o desgaste superficial pode aumentar, diminuir ou manter as propriedades originais de atrito da interface geossintética, repercutindo, diretamente, sobre a estabilidade desta sob condição de serviço.

Palavras-chave: Interface geossintética, desgaste superficial, atrito, geomembrana.

\begin{abstract}
This article presents the results of an experimental study which aimed to evaluate the effect of surface wear on the friction properties of geosynthetic interfaces constituted of geomembranes and geospacers. The tests were performed in ramp test device, and the results showed the different sensitivities of the interfaces to the wear process. For the particular types of interfaces considered in the experiment, the surface wear can increase, decrease or maintain the original friction properties of the geosynthetic interface, with direct effects on the stability under service condition.
\end{abstract}

Keywords: Geosynthetic interface, surface wear, friction, geomembrane, geospacer.

\section{Introduction}

Geosynthetics is a generic name of a set of industrial polymeric products, whose properties contribute to the improvement of civil engineering works, playing one or more of the following functions: strengthening, filtration, drainage, protection, separation, waterproofing and control of surface erosion (Koerner, 1998). The advent of geosynthetics revolutionized several aspects of project and construction of civil engineering works and, in particular, of works for environmental protection. In these works, almost all types of geosynthetics can be employed, fulfilling their typical functions (Vilar, 2003).

Regarding particularly the waterproofing, polymeric geomembranes correspond to a particular type of geosynthetics 
developed to provide more protection to the environment in order to minimize the percolation of contaminant liquids and gases from the degradation of residuals generated by human activities, preventing them to reach the air, soil and groundwater. This is a two dimensional product of very low permeability, predominantly composed of asphalts, elastomers or plastomers, used for flow control and separation, under service conditions.

In general, the geomembranes are not employed separately; they are frequently in contact with other geosynthetics or natural materials, constituting a composite coating system. When in contact with other material, a geomembrane constitutes an interface and, under service conditions, the properties of one or both components of this interface can be altered. In this context, the wear is the process which implies in the alteration of the surface characteristics of a geosynthetics when it interacts with other material or surface.

In civil works aiming to protect the environment (landfill sites, ponds containment and treatment of industrial waste) interfaces which contemplate geomembranes are generally arranged on inclined surfaces to ensure that the volume of stored tailings occupies the smallest area possible (Sharma and Lewis, 1994). Therefore, there is a natural tendency for the components of an interface to slide in

\section{Materials}

The materials employed in the research intended to characterize the wear resistance of geosynthetic interfaces constituted of geomembranes are listed in the Table 1. These materials included smooth polymeric geomembranes (GM) of High-Density Polyethylene (HDPE),

Polyvinyl Chloride (PVC) and Polypropylene (PP) and a geosynthetic product based on High-Density Polyethylene (HDPE), called geospacer (GS), which is frequently employed together with geomembranes in works for environmental protection, having the essential function of drainage relation to each other, but this tendency will be resisted by the interface friction between the materials. However, as this displacement is almost always inevitable, the promoted surface wear can alter deleteriously the frictional characteristics of the interface, contributing thus to a gradual instability increase of the coating system. Additionally, the processes of expansion and contraction induced by the variation in temperature, the processes of damage of geosynthetic surfaces during the installation of the product under construction and during the other stages of the constructive process can enhance the degree of surface wear of interfaces constituted by such polymeric materials.

Thus, the knowledge of the sensitivity of a geosynthetic interface to the wear mechanism triggered at its installation in civil engineering works is an important design issue that should be considered by the manufacturers of geosynthetics, by the project designers and by the executors of the work. The differences among the respective hardness of materials based on PVC (Polyvinyl Chloride), PE (Polyethylene), HDPE (High-Density Polyethylene), LDPE (Low-Density Polyethylene) and VLDPE (Very-Low-Density Polyethylene) and how these differences can affect the behavior of these materials are well documented and reinforce the importance to study the susceptibility of geosynthetic systems to the wear process under conditions similar to service conditions. In addition to the material hardness conveyed by the polymeric constitution, the surface roughness (smooth or rough surface), the nature of contact material (natural or synthetic) and the level of normal stress acting on the interface are also factors governing the mechanism of interface wear (Dove, 1996; Dove et al., 1997; Lee et al., 1998; Zettler et al., 2000; Frost and Lee, 2001; Frost et al., 2002).

In this context, the goal of this experimental study was to characterize the wear resistance of geosynthetic interfaces, considering three different smooth geomembranes of distinct polymeric constitutions in contact with a second geosynthetic material (geospacer). The tests were carried out employing a ramp test device, which allows reproducing on the studied interface the low normal stresses found in conditions of service of the coating systems of environmental works constituted by these materials. Several studies drawing a parallel between ramp test device and shear box shown that the ramp test is a more appropriate device for the characterization of geosynthetic friction under normal stress lower than $10 \mathrm{kPa}$, which is typical of capping systems. In contrast, the direct shear box performs well under higher normal stresses as is common in bottom liners of landfill (Reyes-Ramirez and Gourc, 2003; Palmeira, 2009).

(Figure 1). The geomembranes $\mathrm{GM}_{\mathrm{HDPEa}}$ and $\mathrm{GM}_{\text {HDPEb }}$ have essentially the same surface aspect and the same polymeric composition, however from different manufactures. Two geospacers of different thickness and surface structures were employed (GS8 and GS6).

Table 1

Main characteristics of geosynthetics employed in the research on the wear resistance of geosynthetic interfaces.

\section{Methods}

\section{Ramp test device}

The setup for the tests of the wear resistance of geosynthetic interfaces is presented in the Figure 2, which contemplates the characteristic base system of the conventional ramp test device (Figure 2A, 2B), as well as the following 
Figure 1

Geospacers employed in the research.

elements (Figure 2C):

a. A movable metal plate (A), which allows to receive the test sample of the upper geosynthetic $(\mathrm{C})$, which is bonded on a wood plate (B).

b. A wood plate (B) with dimensions of $18 \mathrm{~cm}$ (in the direction of sliding) by $70 \mathrm{~cm}$ (in the direction transversal to the sliding).

c. Metal plates (D) whose dimensions are similar to the wood plate $\left(18 \times 70 \mathrm{~cm}^{2}\right)$ and serve as overload.

The initial normal stress (support plane at horizontal position) corresponds to $\sigma_{0}=\mathrm{P} / \mathrm{A}$, where $\mathrm{P}$ is the total weight applied on the contact

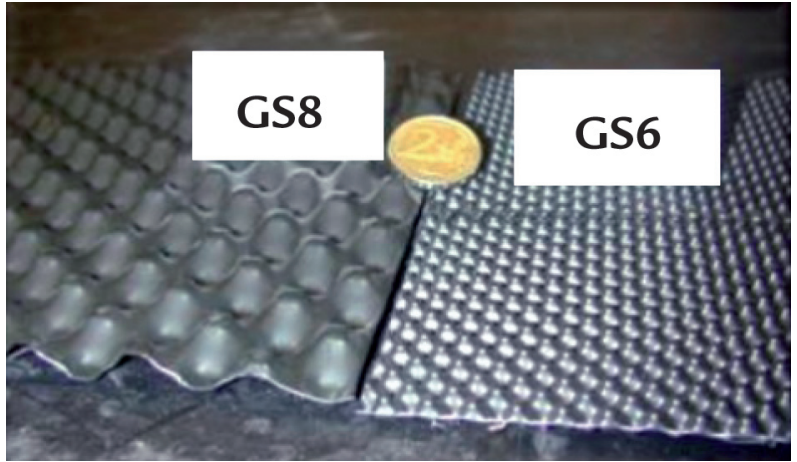

surface (including the support wood plate to which the upper geosynthetic is bonded), and A is the contact area $\left(18 \times 70 \mathrm{~cm}^{2}\right)$. The initial normal stress is obtained with the aid of metal plates (Figure 2C, D) attached to the movable metal plate (Figure 2C, A) with screws. The lower geosynthetic sample is fixed to the support plane of the equipment (80 cm width by $130 \mathrm{~cm}$ length) and anchored on the top through a securing device. The movable plate is equipped with side guides (spherical contacts), which allow a rectilinear sliding, nondiverted regarding the sliding direction (Figure 2C, A). This guidance system is assumed without lateral frictions, enabling thus a total transference of the normal stress to the geosynthetic interface. The inclined plane device is constituted of a rigid base whose lower extremity tends to rotate around a horizontal axis, resulting in the inclination of the plane. Thus, at the beginning of the test, the inclined plane device is at horizontal position, and as the plane becomes inclined (at an angular velocity of $3 \%$ minute), the displacements of the movable plate with the geospacer $[\delta(t)]$ and the angle of inclination of the rigid base $[\beta(\mathrm{t})]$ are recorded by the data acquisition system.

\section{A}

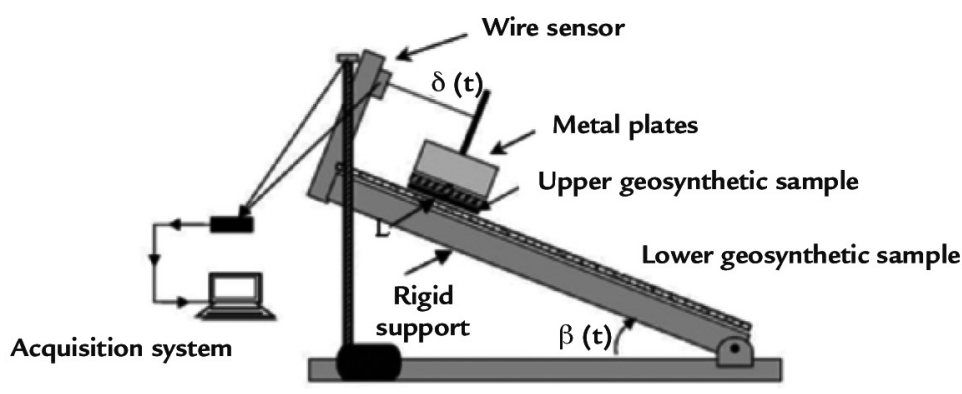

Figure 2

Setup of the ramp test device for performing wear resistance tests of geosynthetic interfaces:

(A) General scheme of the ramp test device.

(B) Ramp test device with movable plate system.

(C) Scheme of the upper movable plate system.

B

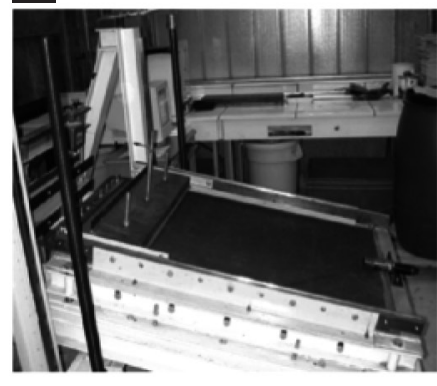

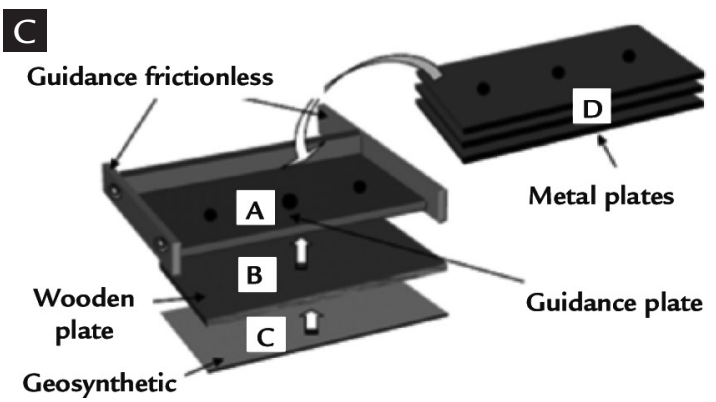

\section{Wear resistance tests}

In this analysis, it was tested several times the same sample of the upper geosynthetic component of the interface. In every test (numbered from $j=1$ to $n$ ), the upper geosynthetic slides until a given displacement, resulting in a cumulative wear on its surface arising from the interaction with the lower geosynthetic upon which the upper geosynthetic slides. The tangential displacement during a given test $(\delta)$ is identified with the purpose to differentiate it from the total tangential displacement $(\Delta)$ suffered by the sample throughout the series of tests, with $\Delta_{0}$ representing the cumulative displacement at the beginning of the test and $\Delta_{f}$ the displacement at the end (for test 1: $\Delta_{0}=0 \mathrm{~mm}, \Delta_{f}=300 \mathrm{~mm}$, for instance).
It was considered an initial normal stress of $\sigma_{\mathrm{o}}=5 \mathrm{kPa}$. Besides, it was exclusively considered the cumulative displacement on the surface of the upper geosynthetic (the one which slides). Thus, at every test cycle, the upper geosynthetic (bonded to the wood plate) was maintained, while the lower geosynthetic (fixed to the support plane and upon which the upper 
geosynthetic slides) was replaced by a new virgin sample.

In this research, the surface wear resistance imposed to the geosynthetic interface was indirectly assessed by the variation in the sliding angle $\beta_{\text {lim }}$ of the upper geosynthetic component of this interface by the end of each wear cycle, as illustrated in the Figure 3.

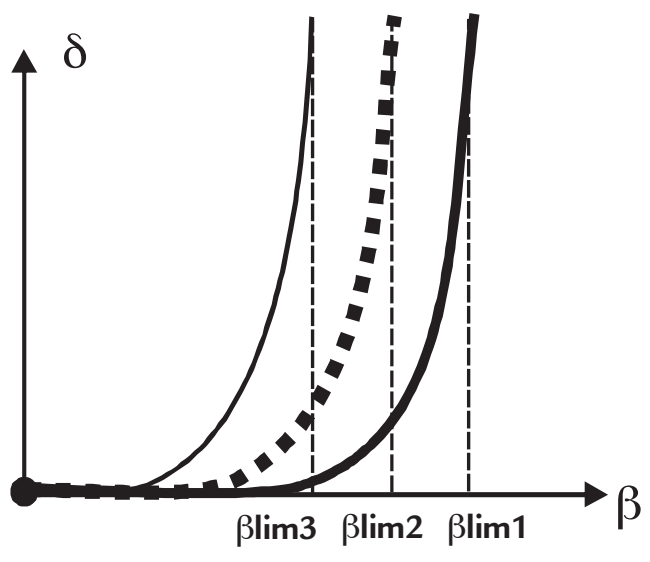

Figure 3

Displacement curves $\delta$ as a function of the inclination of the base plane $\beta$ for each wear cycle imposed to the interface.

\section{Results and discussion}

The Figure 4 and the Table 2 show the results for the wear resistance tests corresponding to the geospacer-geomembrane interfaces of HDPE, geospacergeomembrane of PP and geospacer-geomembrane of PVC. In these tests, a same sample of geospacer was slid several times upon virgin geomembrane samples. Every wear cycle [sequences (1), (2) and (3)] and the cumulative displacement on the upper geosynthetic surface at the end of that cycle (in $\mathrm{mm}$ ) were identified.

For the interfaces between the respective geospacers (GS8 and GS6) and the geomembrane of HDPE, the curves $\delta(\beta)$ were moved to the right at the end of every cycle, showing that this increased the friction between the interface components, being necessary, therefore, higher slopes to promote the geospacer sliding upon the geomembrane $\left(\beta_{\text {lim }} 1<\beta_{\text {lim }} 2<\beta_{\text {lim }} 3\right)$. This was contrary to the presented by the interface between the geospacer GS6 and the geo- membrane of PP, whose curves $\delta(\beta)$ were displaced to the left at the end of every wear cycle, evidencing a reduced friction in the interface contact as increased the wearing imposed by the geomembrane to the geospacer surface. In this case, the system required increasingly smaller slopes for the sliding of the upper geosynthetic on the lower $\left(\beta_{\text {lim }} 1>\beta_{\text {lim }} 2>\beta_{\text {lim }} 3\right)$.

In the case of the interface between the geospacer and the geomembrane of PVC, there was essentially no change in its behavior given increased surface wear on the geospacer. This was evidenced by the overlap of curves $\delta(\beta)$. Thus, the friction mobilized during the upper geosynthetic sliding on this geomembrane was similar for the performed wear cycles $\left(\beta_{\text {lim }}\right.$ approximately constant).

A second set of tests considered the geomembrane as element sliding on the geospacer leaned on the base plane of the inclined plane device (geomembrane-
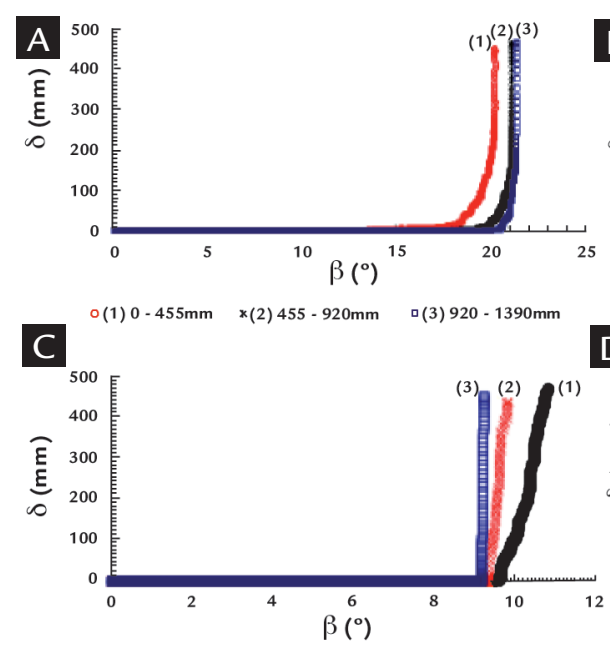

- (1) $0-455 \mathrm{~mm} \times(2) 455-880 \mathrm{~mm} \quad \square$ (3) $880-1320 \mathrm{~mm}$

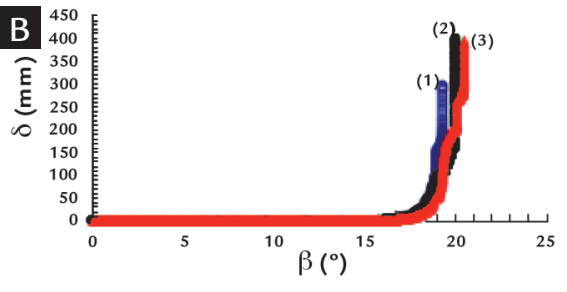

o (1) $0-300 \mathrm{~mm} \quad$ (2) $300-700 \mathrm{~mm} \triangle(3) 700-1100 \mathrm{~mm}$
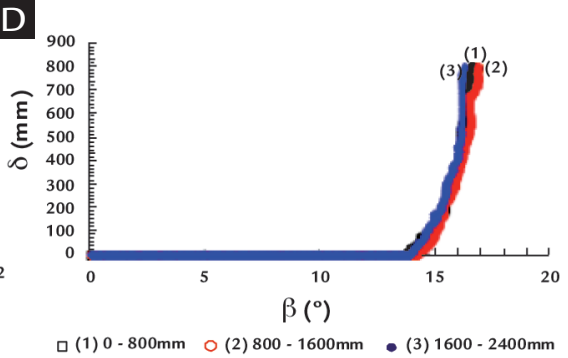

geospacer interface). This is a setup inverse to that previously tested, since the relative position among the components of the interface had been changed. The Figure 5 and the Table 3 show the results of the wear resistance tests on the interfaces of this new setup.

In these tests, a same sample of geomembrane was slid several times upon virgin samples of geospacer. Every wear cycle [sequences (1), (2), (3), (4)] and the cumulative displacement on the upper geosynthetic surface at the end of that cycle (in $\mathrm{mm}$ ) were identified. Distinct responses to the process of surface wear were presented by these configurations. For the $\mathrm{GM}_{\mathrm{PEADb}}-\mathrm{GS} 6$ interface, it was observed a reduced friction of interface at the end of the second cycle of surface wear $\left(\beta_{\text {lim }} 2<\beta_{\text {lim }} 1\right)$, being this cycle responsible for irreversible changes on the geomembrane surface, once the subsequent cycle does not alter the resistant properties of
Figure 4

Results of wear resistance tests of geospacer-geomembrane interfaces:

(A) GS8-GM HDPEa $_{\text {interface. }}$

(B) GS6-GM HDPEa $_{\text {interface. }}$

(C) GS6-GM $M_{P P}$ interface.

(D) GS6-GM ${ }_{\text {PVC }}$ interface. 
Table 2

Data extracted from wear resistance tests for the geospacergeomembrane interfaces.
Results of wear resistance tests of geomembrane-geospacer interfaces: (A) $\mathrm{GM}_{\mathrm{HDPEb}}-\mathrm{GS} 6$ interface. (B) $G M_{\mathrm{HDPEb}}-\mathrm{GS} 8$ interface.

Table 3

Data extracted from wear resistance tests of geomembrane-geospacer interfaces.

this interface $\left(\beta_{\text {lim }} 2 \approx \beta_{\text {lim }} 3\right)$. The $\mathrm{GM}_{\mathrm{PEADb}}{ }^{-}$ GS8 interface, in turn, presented during the first wear cycle an atypical behavior characterized by a phenomenon called "stick-slip". This phenomenon can be explained by the occurrence of successive textural modifications produced by the surface wear, which lead to change the friction properties of this interface, generating successive zones of static behavior (levels of constant displacement with $d \delta /$ $d \beta \rightarrow 0$ ), followed by zones of dynamic behavior (ranges of sudden increase in displacement with $d \delta / d \beta \rightarrow 8)$. The subsequent wear cycles not only increased the interface friction, but also eliminated the tendency to the "stick-slip" as previously identified, conducting the interface to a sudden sliding. This aspect enhanced the

\begin{tabular}{c|c|c|c|c|c|c|c|c|c|c|c|c}
\hline Interface & \multicolumn{3}{|c|}{ GS8-GM $_{\text {HDPEa }}$} & \multicolumn{2}{|c|}{ GS6-GM $_{\text {HDPEa }}$} & \multicolumn{3}{c|}{ GS6-GM $_{\text {PP }}$} & \multicolumn{3}{c}{ GS6-GM $_{\text {PVC }}$} \\
\hline Wear cycle & 1 & 2 & 3 & 1 & 2 & 3 & 1 & 2 & 3 & 1 & 2 & 3 \\
\hline$\Delta_{\mathrm{o}}(\mathrm{mm})$ & 0 & 455 & 920 & 0 & 300 & 700 & 0 & 455 & 880 & 0 & 800 & 1600 \\
\hline$\Delta_{\mathrm{f}}(\mathrm{mm})$ & 455 & 920 & 1390 & 300 & 700 & 1100 & 455 & 880 & 1320 & 800 & 1600 & 2400 \\
\hline$\beta_{\text {lim }}\left({ }^{\circ}\right)$ & 20.2 & 21.1 & 21.4 & 19.3 & 20.0 & 20.5 & 10.7 & 9.8 & 9.2 & 16.7 & 16.9 & 16.3 \\
\hline
\end{tabular}

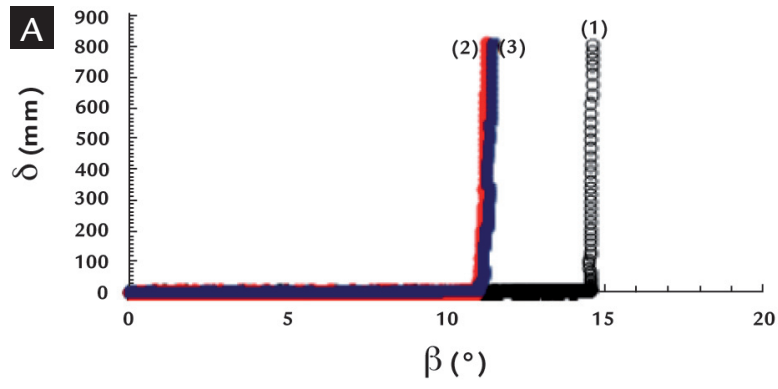

○ (1) $0-800 \mathrm{~mm} \quad$ (2) $800-1600 \mathrm{~mm} \quad$ (3) $1600-2400 \mathrm{~mm}$

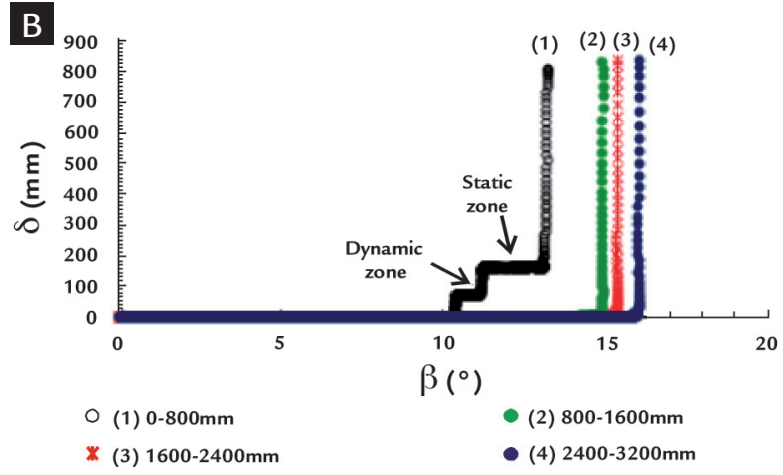

\begin{tabular}{c|c|c|c|c|c|c|c}
\hline Interface & \multicolumn{3}{|c|}{ GM $_{\text {HDPEb }}$-GS6 } & \multicolumn{4}{c}{ GM $_{\text {HDPEb }}$-GS8 } \\
\hline Wear cycle & 1 & 2 & 3 & 1 & 2 & 3 & 4 \\
\hline$\Delta_{\mathrm{o}}(\mathrm{mm})$ & 0 & 800 & 1600 & 0 & 800 & 1600 & 2400 \\
\hline$\Delta_{\mathrm{f}}(\mathrm{mm})$ & 800 & 1600 & 2400 & 800 & 1600 & 2400 & 3200 \\
\hline$\beta_{\text {lim }}\left({ }^{\circ}\right)$ & 14.6 & 11.3 & 11.5 & 13.2 & 14.9 & 15.4 & 16.0 \\
\hline
\end{tabular}

sensitivity of the geosynthetic interface to the wear process.

With the set of experimental results, previously presented and exclusively considering the geosynthetic materials employed herein, it was possible to notice that:

- The sensitivity of geosynthetic interfaces to the surface wear process was closely dependent on the particular type of geomembrane component of the interface: in contact with the geospacer of $6 \mathrm{~mm}$ (GS6), the geomembrane of HDPE increased the interface properties of friction, while the interface of this geospacer together with the geomembrane of polypropylene (PP) had its friction reduced with the surface wear; in turn, the surface wear imposed to the geospacer surface by the PVC geomembrane did not modify the magnitude of the friction mobilized on the interface.

- This sensitivity was dependent on the relative position among the geosynthetic elements components of the interface: when the geospacer GS6 was slid upon the HDPE geomembrane, being superficially worn by the geomembrane, the friction of interface increased with the wear process; when the geomembrane of HDPE was slid upon the geospacer GS6, the interface friction was reduced.

- This sensitivity was dependent on the structure of the geosynthetic elements components of the interface: when the 
HDPE geomembrane was slid upon the geospacer GS6, the friction of interface decreased with the surface wear; when this geomembrane was slid upon the geospacer of $8 \mathrm{~mm}$ (GS8),

\section{Conclusions}

Geosynthetic interfaces are sensitive to the surface wear process. This sensitivity has consequences in friction properties, and it may increase or decrease their stability under the conditions of service typical to which when subjected in works. The damaging effect due to the relative tangential displacement can increase or decrease the interface friction, depending of the pair of associated geosynthetics. The particular type of geomembrane component of a geosynthetic interface plays an important role in the response of this interface to the

\section{Acknowledgements}

The authors thank to the partnership Capes-Cofecub for the financial the interface friction was enhanced by this process.

- According to the particular type of geomembrane component of an interface, the form of rupture or of sliding of an interface subjected to the surface wear can be drastically changed (sliding "stick-slip" transformed into sudden sliding, for instance). surface wear process. Additional factors such as the relative position among the elements of the interface and the structure of these elements also interfere with the mechanism of wear resistance. Conditions of deployment of the geosynthetic lining systems on slopes, initial wrinkles, and individual conditions of tensile mobilization of the geosynthetics might induce large relative displacements at the interfaces. For these large displacements, which are not considered in the standard interpretation, the alteration of the geosynthetic surface

support and FAPEMIG for supporting the article.

\section{References}

DOVE, J.E. Particle-geomembrane interface strength behavior as influenced by surface topography. Atlanta, Georgia, USA: School of Civil and Environmental Engineering, Georgia Institute of Technology, 1996. 323 p. (Ph.D. Dissertation).

DOVE, J.E., FROST, J.D., HAN, J., BACHUS, R.C. The influence of geomembrane surface roughness on interface strength. In: GEOSYNTHETICS‘97, Proceedings... IFAI, v. 2, Long Beach, California, USA, March 1997, p. 863. 1997.

FROST, J.D., LEE, S.W. Microscale study of geomembrane-geotextile interactions. Geosynthetics International, v. 8, n. 6, p. 577, 2001.

FROST, J.D., ZETTLER, T.E., DEJONG, J.T., LEE, S.W., KAGBO, S. Strain induced changes in geomembrane surface topography. Geosynthetics International, v. 9, n.1, p. 21, 2002.

KOERNER, R.M. Designing with Geosynthetics. $4^{\text {th }}$ edition. New Jersey: Prentice Hall Inc., Upper Saddle River, 1998.

LEE, S.W., FROST, J.D., RIGHTER, G.K. The influence of geomembrane surface roughness on geomembrane-geotextile interface strength. In: INTERNATIONAL CONFERENCE ON GEOSYNTHETICS, IFAI, 6. Proceedings..., v. 1, Atlanta, Georgia, USA, April 1998, p. 433, 1998.

PALMEIRA, E. M. Soil-geosynthetic interaction: modeling and analysis. Geotextiles and Geomembranes, v. 27, n. 5, p. 368, 2009.

REYES-RAMIREZ, R., GOURC, J. P. Use of the inclined plane test in measuring geosynthetic interface friction relationship. Geosynthetics International, v. 10, n.5, p. 165, 2003.

SHARMA, H.D., LEWIS, S.P. Waste containment system, waste stabilization and landfills: design and evaluation. New York: John Wiley \& Sons, 1994.

VILAR, O.M. Geossintéticos em aplicações ambientais. In: SIMPÓSIO BRASILEIRO DE GEOSSINTÉTICOS - GEOSSINTÉTICOS’2003, 4. Porto Alegre-RS, p. 203, 2003.

ZETTLER, T.E., FROST, J.D., DEJONG, J.T. Shear-Induced Changes in Smooth HDPE Geomembrane Surface Topography. Geosynthetics International, v. 7, n.3, p. 243, 2000.

Artigo recebido em 04 de julho de 2012. Aprovado em 19 de março de 2013. 